\title{
Influence of Silica Fumes on Compressive Strength and Wear Properties of Glass Ionomer Cement in Dentistry
}

\author{
Anand Meganadhan ${ }^{1}$, Kavitha Sanjeev², Mahalaxmi Sekar ${ }^{3}$ \\ 1,2,3 Department of Conservative Dentistry and Endodontics, SRM Dental college, \\ SRM Institute of Science and Technology, Chennai, India.
}

\section{ABSTRACT}

\section{BACKGROUND}

Glass ionomer cements (GIC) are an interesting restorative option due to their biocompatibility. However, it has limitations that challenge its survival in oral environment due its porous set matrix influencing the properties of the cement. This study was conducted to evaluate the influence of the addition of varying concentrations of silica fumes (SF) on the properties of GIC by field emission scanning electron microscopy [FESEM] and energy-dispersive spectroscopy [EDX]. The final set matrix of GIC remains porous, compromising the mechanical properties, limiting its extended use clinically. Incorporation of silica fumes, a pozzolan, as an additive in GIC serves as a potential filler by increasing its compressive strength and reducing wear properties.

\section{METHODS}

The cement was divided into 5 groups based on the absence or presence of varying concentrations $(0.5,1,1.5,2 \%)$ of silica fumes; conventional glass ionomer group (CG) (I) and 0.5, 1, 1.5, 2 silica fumes incorporated glass ionomer cement (SG) (II, III, IV \& V) respectively. Compressive strength and wear resistance were subjected to Universal Testing Machine and Pin on Tribometer respectively. The microstructure and the elemental composition of prepared specimens of all the groups were evaluated using FESEM and EDX. Data obtained was analysed using Statistical Package for the Social Sciences (SPSS) V22.0 (IBM, USA) followed by one-way analysis of variance (ANOVA) and post hoc Tukey test $(\mathrm{P}<0.05)$.

\section{RESULTS}

Except 0.5SG, increased compressive strength and decreased wear of glass ionomer material was observed as the concentration of silica fumes increased. Of all the concentrations, 2SG had significantly increased compressive strength (221.62 \pm $22.84 \mathrm{MPa})$ compared to $\mathrm{CG}(167.38 \pm 36.94 \mathrm{MPa})(\mathrm{P}<0.05)$. Significantly increased resistance to wear was noted in $2 \mathrm{SG}(11.80 \pm 2.58 \mu \mathrm{m})$ compared to CG $(20.40 \pm 2.07$ $\mu \mathrm{m})(\mathrm{P}<0.05)$. The set matrix of silica fumes modified GIC showed minimal / absence of pores with dispersion of crystalline particles as the concentration of SF increased. EDX revealed similar constitution of minerals but, varied with increased concentration of silica fumes.

\section{CONCLUSIONS}

$2 \%$ silica fumes incorporated glass ionomer cement (2SG) enhanced the properties of conventional glass ionomer cement.

\section{KEY WORDS}

Compressive Strength, EDX, Field Emission Scanning Electron Microscope, Glass Ionomer Cement, Silica Fumes, Pozzolan
Corresponding Author: Dr. Kavitha Sanjeev, Professor, Department of Conservative Dentistry and Endodontics, SRM Dental College, SRM Institute of Science and Technology. Chennai, India.

E-mail: researchkavi02@gmail.com

DOI: $10.14260 /$ jemds/2021/306

How to Cite This Article:

Meghanadhan A, Sanjeev $K$, Sekar M. Influence of silica fumes on compressive strength and wear properties of glass ionomer cement. J Evolution Med Dent Sci 2021;10(20):1457-1462, DOI: 10.14260/jemds/2021/306

Submission 04-11-2020,

Peer Review 30-01-2021,

Acceptance 06-02-2021,

Published 17-05-2021.

Copyright (C) 2021 Anand Meghanadhan et al. This is an open access article distributed under Creative Commons Attribution License [Attribution 4.0 International (CC $B Y 4.0)]$ 


\section{BACKGROUND}

The desirable properties of conventional glass-ionomer cement (CG) is characterised by its acid-base reaction. This makes it a unique restorative material.1,2 Its excellent adhesion to the tooth substrate results in effective marginal sealing. In addition, its ability to release fluoride ions into the surrounding oral tissues prevents and controls tooth decay. ${ }^{3}$ GIC hardens on setting, but under microscopic examination, the matrix reveals presence of irregularly shaped particles dispersed throughout the matrix. Apart from this, a high percentage of pores are being observed distributed unevenly throughout the matrix irrespective of the manipulative techniques. ${ }^{4,5}$ Nomoto $\mathrm{R}$ et al. stated that the incorporated porosity in the set matrix of GIC can be one of the factors influencing the mechanical properties of the material. ${ }^{6}$ Furthermore, Daniela et al. has stated that the percentage of porosity and the microstructure of the material has a direct influence not only on its compressive strength, but wear of the material as well. ${ }^{7}$ Hence, its relatively low mechanical strength and wear resistance consequently results in changes in restorative anatomy, simultaneously increasing the surface roughness thus limiting its use in high stress bearing areas as a restorative material.2,8

Several attempts have been made to enhance the properties of, namely incorporation of casein phosphopeptide-amorphous calcium phosphate, hydroxyapatite and bioactive glass. Though significant improvements have been made, continued search is still going on to further enhance its properties, as lack of strength and lack of wear resistance still remain a major concern.9.10

Silica fumes (SF), a fined separated silica containing high percentage of silicon dioxide is obtained during filtration of the exhaust gases as fumes from the furnaces in industries. It was first recognised and obtained in Norway in $1947 .{ }^{11}$ It is a highly reactive pozzolanic material, with enhanced mechanical properties. ${ }^{12}$

Incorporation of micro silica in concrete resulted in increased strength and durability. Its finely sized particle and increased surface area is reported to fill in the pores producing a cohesive and denser substance when incorporated into a material. ${ }^{13}$ This study was conducted to incorporate SF in to evaluate the conventional glass ionomer cement's effect on the compressive strength and wear resistance of the cement. Null hypothesis is that, incorporation of SF in GIC does not have any influence on the properties.

\section{METHODS}

\section{Experimental Procedures}

Preparation of SF Modified CG (SG)

CG and SF were obtained from (GC Fuji II, GC India Dental Pvt. Ltd., Lot no: 1607041) and (Silica Fumes, Astrra chemicals, Chennai, Lot no: 20170806) respectively. SF in three different proportions were weighed using analytical balance (Sartorius scales, Germany) and mixed with corresponding weight percentage of GIC powder and allotted to five groups as follows:

\section{Grouping}

- Group-I- CG (without addition of SF)

- Group-II- 0.5 SG (99.5 mg CG + 0.5 mg SF)

- Group-III- 1 SG (99.0 mg CG + 1 mg SF)

- $\quad$ Group-IV- 1.5 SG (98.5 mg CG + 1.5 mg SF)

- Group-V- 2 SG (98.0 mg CG + 2 mg SF)

CG powder and SF were blended together using mortar and pestle and sieved to get a homogenous powder.

\section{Specimen Preparation}

Compressive Strength ( $n=5$ each)

The above combinations were mixed with the desired polyacrylic acid until the desired paste like consistency was obtained. The manipulated materials were packed into the custom-made polytetrafluorethylene molds measuring $5 \mathrm{~mm}$ by $4 \mathrm{~mm}$ and were compacted. The excess material was removed from the mold and stored at $37^{\circ} \mathrm{C}$ at $95 \%$ humidity until use. Subsequently, the specimens were subjected to Universal Testing Machine UTM (Tec-Sol, Chennai, India) at the speed of $0.05 \mathrm{~mm} / \mathrm{min}$ with the load of $5 \mathrm{kgs}$. The obtained values were converted into megapascals (MPa).

Wear Resistance ( $n=5$ each)

Specimens with $10 \mathrm{~mm} \times 2 \mathrm{~mm} \times 2 \mathrm{~mm}$ dimensions were prepared, and were subjected to pin on disc tribometer after 7 days following storage in $95 \%$ humidity at $37^{\circ} \mathrm{C}$, to analyse the wear resistance. The specimens acted as a pin which were been abraded against a stainless steel disc with $350 \mathrm{rpm}$ of rotational speed. A load of $2 \mathrm{~kg}$ was applied constantly over the specimen, following 10 minutes, the depth of wear was noted.

\section{Microstructure of Set Cement ( $n=5$ each)}

Samples of dimension $5 \mathrm{~mm} \times 5 \mathrm{~mm}$ were prepared and fixed on a stub, and viewed under field emission scanning electron microscope (FESEM, FEI Quanta 400, Netherlands) under x20000 magnification for analysis of microstructure. The elemental composition of the samples was analysed using energy-dispersive x-ray spectroscopy EDX (FEI Quanta 400, Netherlands) by area mode of the outer and the inner surface on five parts of each sample at random. The results were noted based on their average.

This was an in-vitro study conducted between August 2019 - January 2020.

\section{Statistical Analysis}

Data was analysed using Statistical Package for the Social Sciences (SPSS) statistics V22.0 (IBM, USA). One-way analysis of variance (ANOVA) and post hoc Tukey test were applied and the level of significance was set at $\mathrm{P}<0.05$.

\section{RESULTS}

Statistical analysis for compressive strength and wear resistance are represented in (Table 1 - 2) respectively. All the experimental groups except $0.5 \mathrm{SG}$ showed increased compressive strength compared to CG. 


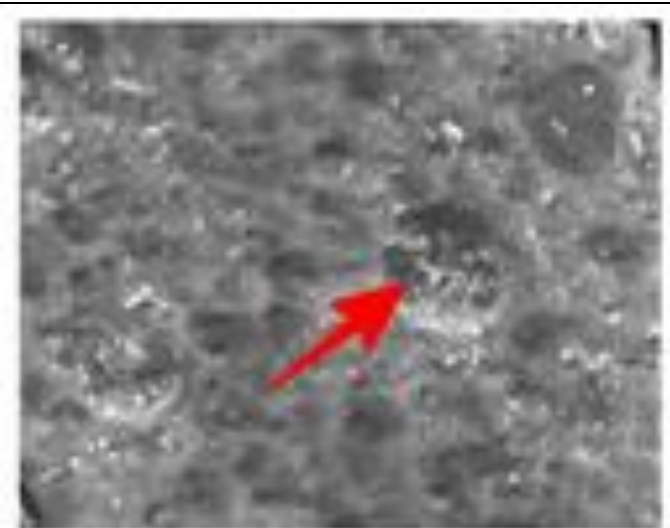

CG

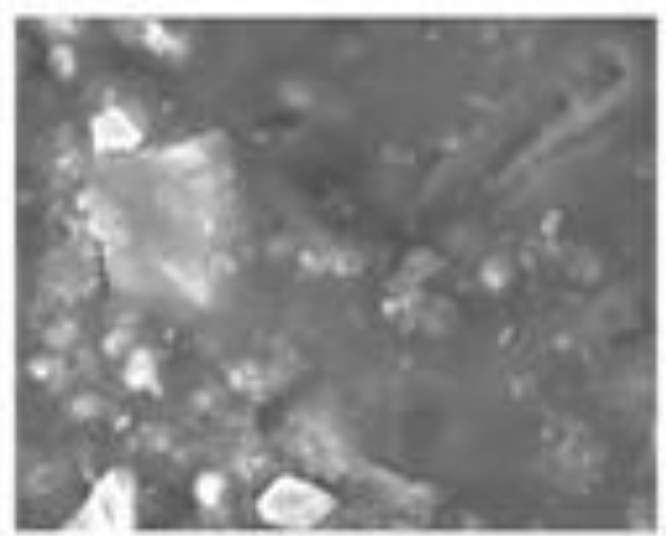

1 SG

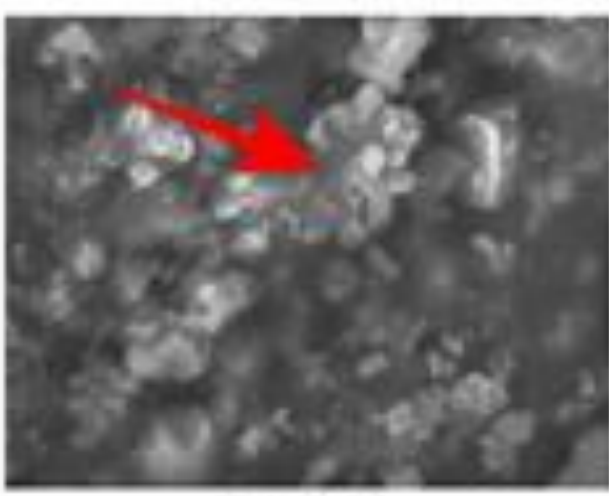

2 SG

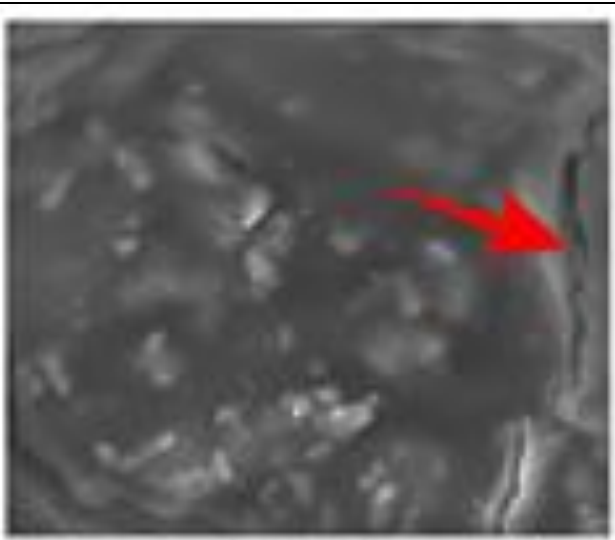

0.5 SG

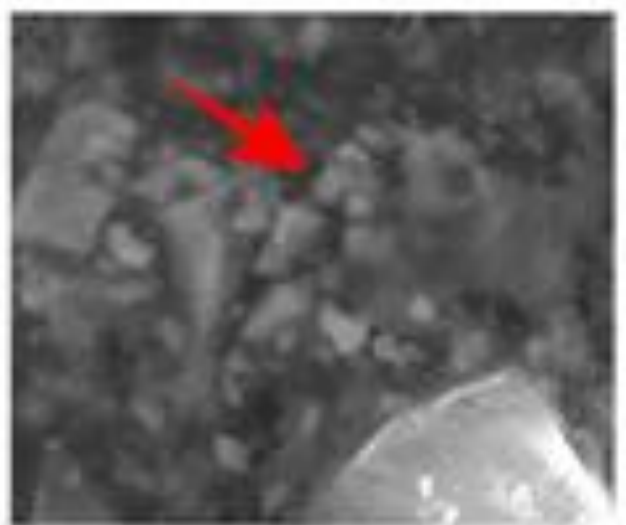

$1.5 \mathrm{SG}$

Figure 1. SEM Micrographs of All the Groups. CG - Presence of Pores and Craters on the Surface of the Set Matrix (Red Arrow); 0.5 SG - Presence of Cracks in the Set Matrix (Red Arrow). 1SG, 1.5SG, 2SG - Presence of Crystalline Particles Distributed Throughout the Matrix (Red Arrow)

\begin{tabular}{|c|c|c|c|c|c|c|}
\hline Groups & Mean & $\begin{array}{l}\text { Std. } \\
\text { Dev. }\end{array}$ & $\begin{array}{l}\text { Std. } \\
\text { Error }\end{array}$ & $\begin{array}{c}\quad 95 \% \\
\text { Confidence } \\
\text { Interval for } \\
\quad \text { Mean } \\
\text { Lower Upper } \\
\text { Bound Bound }\end{array}$ & Minimum & $\begin{array}{l}\text { Maximu } \\
\text { m }\end{array}$ \\
\hline CG & 167.3820 & $\begin{array}{c}36.9471 \\
2\end{array}$ & 16.52325 & $121.5061 \begin{array}{c}213.257 \\
9\end{array}$ & 134.37 & 226.00 \\
\hline $0.5 \mathrm{SG}$ & 165.3560 & $\begin{array}{c}48.5797 \\
7\end{array}$ & 21.72553 & $105.0363 \begin{array}{c}225.675 \\
7\end{array}$ & 122.00 & 224.54 \\
\hline 1SG & 187.0720 & $\begin{array}{c}29.8389 \\
0\end{array}$ & 13.34436 & $150.0221 \begin{array}{c}224.121 \\
9\end{array}$ & 152.11 & 227.58 \\
\hline $1.5 \mathrm{SG}$ & 188.9260 & $\begin{array}{c}51.9116 \\
0\end{array}$ & 23.21557 & $124.4692 \begin{array}{c}253.382 \\
8\end{array}$ & 134.01 & 263.37 \\
\hline $2 \mathrm{SG}$ & 221.6240 & $\begin{array}{c}22.8498 \\
0\end{array}$ & 10.21874 & $\begin{array}{c}193.2522 \\
249.995 \\
8\end{array}$ & 186.49 & 248.62 \\
\hline \multicolumn{7}{|c|}{$\begin{array}{l}\text { Table 1. Descriptive One-Way Analysis for Compressive Strength } \\
\text { Values for All the Groups (MPa) }(N=5)\end{array}$} \\
\hline $\begin{array}{l}\text { Abbrevi } \\
\text { Modifie }\end{array}$ & iations: & $\begin{array}{l}\text { G - Conv } \\
\text { ational G }\end{array}$ & $\begin{array}{l}\text { jentional } \mathrm{C} \\
\text { lass-Ionor }\end{array}$ & $\begin{array}{l}\text { Glass-Ionomer Ce } \\
\text { mer Cement }\end{array}$ & ement; SG & ilica Fume \\
\hline
\end{tabular}

\begin{tabular}{|c|c|c|c|c|c|c|c|}
\hline \multirow{2}{*}{ Groups } & \multirow{2}{*}{ Mean } & \multirow{2}{*}{$\begin{array}{l}\text { Std. } \\
\text { Dev }\end{array}$} & \multirow{2}{*}{$\begin{array}{l}\text { Std. } \\
\text { Error }\end{array}$} & \multicolumn{2}{|c|}{$\begin{array}{l}95 \% \text { Confidence } \\
\text { interval for Mean }\end{array}$} & \multirow{2}{*}{ Minimum } & \multirow{2}{*}{$\begin{array}{l}\text { Maximu } \\
\text { m }\end{array}$} \\
\hline & & & & $\begin{array}{l}\text { Lower } \\
\text { Bound }\end{array}$ & $\begin{array}{l}\text { Upper } \\
\text { Bound }\end{array}$ & & \\
\hline CG & 20.40 & 2.074 & .927 & 17.83 & 22.97 & 18 & 23 \\
\hline $0.5 \mathrm{SG}$ & 19.20 & 2.387 & 1.068 & 16.24 & 22.16 & 16 & 22 \\
\hline 1SG & 16.60 & 2.510 & 1.122 & 13.48 & 19.72 & 13 & 19 \\
\hline $1.5 \mathrm{SG}$ & 16.20 & 2.280 & 1.020 & 13.37 & 19.03 & 13 & 19 \\
\hline $2 \mathrm{SG}$ & 11.80 & 2.588 & 1.158 & 8.59 & 15.01 & 9 & 15 \\
\hline \multicolumn{8}{|c|}{$\begin{array}{l}\text { Table 2. Descriptive One-Way Analysis for Wear Resistance Values for } \\
\text { All the Groups }(\mu \mathrm{m})(N=5)\end{array}$} \\
\hline
\end{tabular}

2SG (221.62 $\pm 22.84 \mathrm{MPa})$ showed significantly higher compressive strength compared to CG $(167.38 \pm 36.94 \mathrm{MPa})$ and other concentrations $(0.5,1,1.5)$ of SG $(165.35 \pm 48.57$ $\mathrm{MPa} ; 187.07 \pm 29.83 \mathrm{MPa} ; 188.92 \pm 51.91 \mathrm{MPa}$ respectively) ( $\mathrm{P}$ $<0.05$ ). 

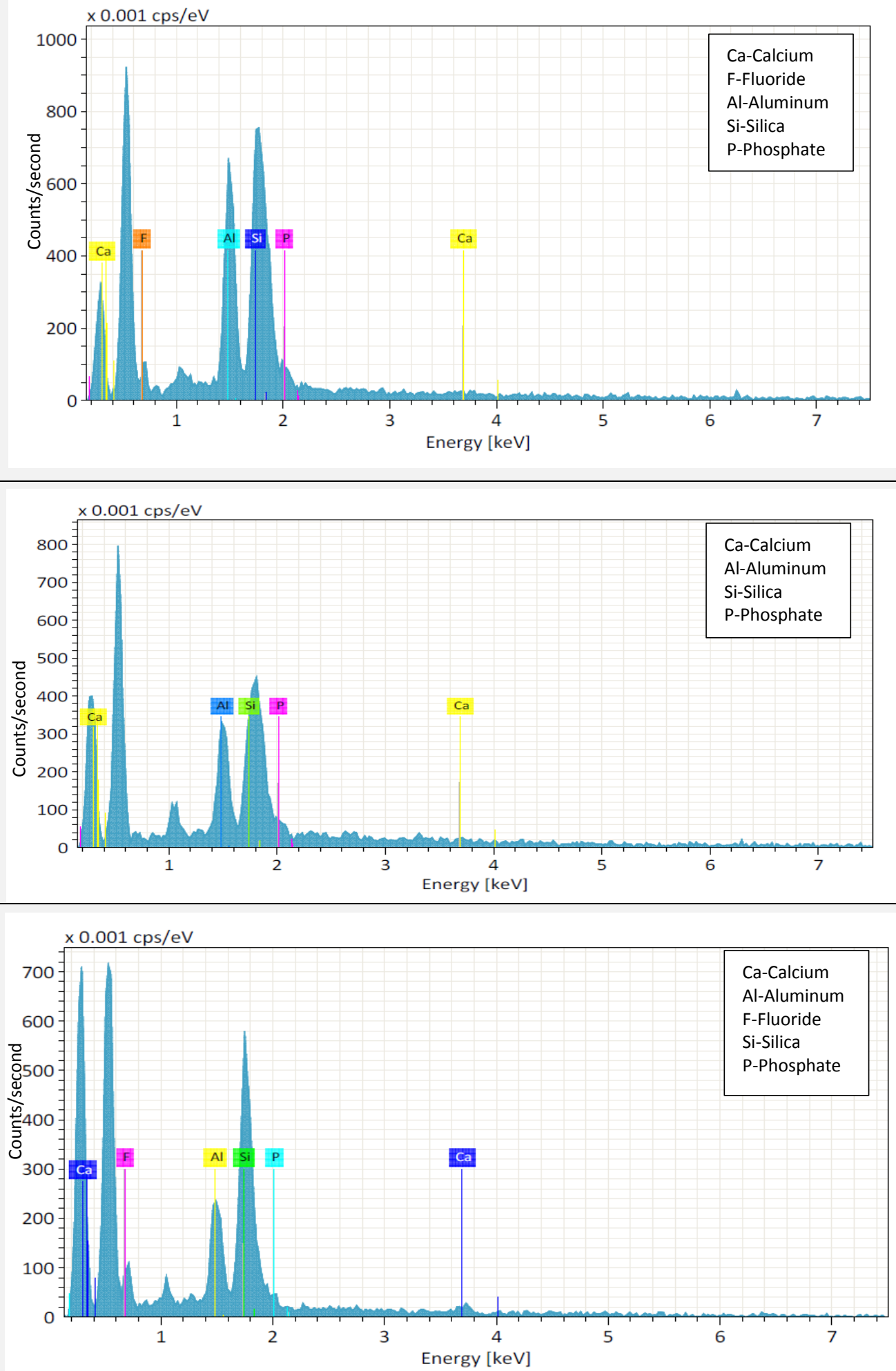

Figure 2. EDX Images of CG, 1.5 and 2 SG (from Top to Bottom)

With regards to wear resistance, though all the experimental groups $(0.5,1,1.5 \mathrm{SG})(19.20 \pm 2.38 \mu \mathrm{m} ; 16.60 \pm$ $2.5 \mu \mathrm{m} ; 16.20 \pm 2.28 \mu \mathrm{m})$ respectively, showed increased resistance to wear compared to $C G(20.40 \pm 2.07 \mu \mathrm{m})$, though they were not statistically significant. 2 SG group $(11.8 \pm 2.58)$ had statistically significant increased resistance to wear compared to other groups $(\mathrm{P}<0.05)$.

Selected FESEM photomicrographs of all the groups and the EDX spectra of elements obtained from the samples (CG,1.5\&2) are represented in Figure $1 \& 2$ respectively. Under
FESEM examination, it was noted that all the surfaces of the examined specimens had morphological changes (Figure1).

The presence of pores, crakes and crystalline particles were evident in few of the specimens (Figure 1). Empty voids ranging in various sizes were observed in the CG group (Figure 1). EDX analysis of the area displayed in the tested groups showed a similar constitution although the values varied (Figure 2). 


\section{DISCUSSION}

In concrete, SF has been acknowledged as a pozzolanic admixture and its use is recognised globally, for its effectiveness in increasing strength and impermeability. ${ }^{13}$ In the present study the incorporation of small quantities of SF as reinforcing fillers has shown considerable impact on compressive strength and wear properties of CG. 2SG showed the highest compressive strength $(221.6 \mathrm{MPa})$ and increased wear resistance $(11.8 \mu \mathrm{m})$ compared to $\mathrm{CG}$ and other concentrations of SF.

Silicon oxide makes up to more than $90 \%$ of the SF. Basically, silica fumes when mixed in a material, being a reactive pozzolan it reacts with the other constituents of the material resulting in a pozzolanic reaction. ${ }^{13}$ As CG contains calcium oxide and sodium oxide $(\mathrm{CaO}$ and $\mathrm{NaO})$ and the glass being a pozzolan itself, SF might have interacted with it, resulting in formation of a more cementitious compound calcium silicate hydrate (C-S-H). ${ }^{14}$

EDX is a precise and reproducible method to quantify the constituents or compounds present in a material. ${ }^{15,16} \mathrm{As}$ observed in EDX, all the tested groups in this study had a similar elemental constitution although the values varied. (Figure 2) The calcium and silicate concentration increased as the concentration of the SF increased. This can be correlated to the formation of calcium silicate hydrate (C-S-H) due to pozzolanic reaction with the glass powder of the cement.

There seemed to be no reducing in the fluoride ions, it means that the anti-bacterial action remains unaffected even with the incorporation of silica fumes.

Furthermore, SF is said to fill in the pores of the setting matrix resulting in better inter particle arrangement, thus, bringing about aggregate paste bonding through its chemical reaction by forming cementitious compound (C-S-H). ${ }^{13}$ Thus the addition of SF to CG could have occupied the porosities present in CG, modifying the set matrix, thereby increasing the compressive strength and wear resistance, confirming the results obtained in this study.

In the present study, the FESEM images of CG and SG represented with cracks in few of the specimens. (Figure 1) Cracks are generally observed due to dryness in the glass ionomer cement. ${ }^{17}$ It can also be due to sample preparation for microscopic analysis, a major limitation. Apart from cracks, there were numerous pores observed in CG, and these were found distributed throughout the whole mass of the cement. This could be related to mixing process, which could have caused air inclusion during manipulation as reported in other studies.6,18,19 Pores in the set matrix act as a source of stress concentration area, subjecting the specimens to brittle fracture ${ }^{20}$ It has been stated that a strong linear relationship exists between the mean porosity and the compressive strength of the cement.18,7 This confirms with the lower compressive strength obtained for CG group. FESEM images of CG and SG clearly indicate that the pores in CG have reduced in size as the incorporation of SF increased. (Figure 1) In Figure 1 (2SG), presence of crystal-like structures that is spread throughout the matrix is suggestive of either particle of SF itself or the formation of $\mathrm{C}-\mathrm{S}-\mathrm{H}$. These crystalline particles seemed to have occupied the pore spaces creating a dense, compact surface architecture. These can be correlated to the increased compressive strength and low wear resistance observed in 2SG when compared to that of CG.

The rationale for the addition of SF into CG emanates from the observation that SF serves as a potential filler increasing the properties of CG. Thus, the null hypothesis of this study was rejected.

\section{CONCLUSIONS}

When silica fumes were incorporated in GIC, reduction of pores in set matrix, with increased compressive strength and lesser resistance to wear was noted. Silica fumes appear to be a promising additive and can be considered to be incorporated in glass ionomer cement. Further studies are needed for maximising silica fumes modified GIC applications.

\section{Limitations}

Though in vitro studies do validate the effect of each situation on the material behaviour, it is not possible to mimic all the conditions of the oral environment. Thus, further, other in vitro evaluation parameters are necessary to validate our findings.

Data sharing statement provided by the authors is available with the full text of this article at jemds.com.

Financial or other competing interests: None.

Disclosure forms provided by the authors are available with the full text of this article at jemds.com.

\section{REFERENCES}

[1] Anusavice KJ, Philips RW, Shen C, et al. Phillip's science of dental materials. $11^{\text {th }}$ edn. St. Louis: Sanders 2005.

[2] McCabe JF, Walls AWG. Applied dental materials. Br Dent J 2009;206:441.

[3] Bonifácio CC, Kleverlaan CJ, Raggio DP, et al. Physicalmechanical properties of glass ionomer cements indicated for atraumatic restorative treatment. Aust Dent J 2009;54(3):233-7.

[4] Geirsson J, Thompson JY, Bayne SC. Porosity evaluation and pore size distribution of a novel directly placed ceramic restorative material. Dent Mater 2004;20(10):987-95.

[5] Xie D, Brantley WA, Culbertson BM, et al. Mechanical properties and microstructures of glass-ionomer cements. Dent Mater 2000;16(2):129-38.

[6] Nomoto R, Komoriyama M, McCabe JF, et al. Effect of mixing method on the porosity of encapsulated glass ionomer cement. Dent Mater 2014;20(10):972-8.

[7] Rodrigues DS, Buciumeanu M, Martinelli AE, et al. Mechanical strength and wear of dental glass-ionomer and resin composites affected by porosity and chemical composition. J Bio Tribo Corros 2015;1(24).

[8] Zimehl R, Hannig M. Nonmetallic restorative materials based on glass ionomer cements-recent trends and developments. Colloids and Surfaces A: Physicochemical and Engineering Aspects 2000;163(1):55-62.

[9] Kumar RS, Ravikumar N, Kavitha S, et al. Nano chitosan modified glass ionomer cement with enhanced 
mechanical properties and fluoride release. Int J Biol Macromol 2017;104 B:1860-5.

[10] Moshaverinia A, Ansari S, Moshaverinia M, et al. Effects of incorporation of hydroxyapatite and fluorapatite nanobioceramics into conventional glass ionomer cements (GIC). Acta Biomater 2008;4(2):432-40.

[11] Choo BS, Newman JB, eds. Advanced concrete technology: concrete properties. $1^{\text {st }}$ edn. Butterworth-Heinemann 2003.

[12] Ransinchung RN, Kumar B. Investigations on pastes and mortars of ordinary portland cement admixed with wollastonite and microsilica. J Mater Civ Eng 2010;22(4).

[13] Jain A, Pawade P. Characteristics of silica fume concrete. Internationa Journal of Computer Applications 2015;8:23-6.

[14] Kumar V, Imam A, Srivastava V, et al. Effect of micro silica on the properties of hardened concrete. International Journal of Engineering Research and Development 2017;13(11):8-12.
[15] Dammaschke T, Gerth HUV, Züchner H, et al. Chemical and physical surface and bulk material characterization of white proroot MTA and two portland cements. Dent Mater 2005;21(8):731-8.

[16] Tay FR, Sano H, Tagami J, et al. Ultrastructural study of a glass ionomer-based, all-in-one adhesive. J Dent 2001;29(7):489-98.

[17] Zoergiebel J, Ilie N. Evaluation of a conventional glass ionomer cement with new zinc formulation: effect of coating, aging and storage agents. Clin Oral Invest 2013;17(2):619-26.

[18] Swift EJ, Dogan AU. Analysis of glass ionomer cement with use of scanning electron microscopy. J Prosthet Dent 1990;64(2):167-74.

[19] Nomoto R, McCabe JF. Effect of mixing methods on the compressive strength of glass ionomer cements. J Dent 2001;29(3):205-10.

[20] McCabe JF, Ogden AR. The relationship between porosity, compressive fatigue limit and wear in composite resin restorative materials. Dent Mater 1987;3(1):9-12. 